\title{
eMental Health Bridges Project: A Web Site Development Project to Provide Needed Mental and Physical Health Information to People with Serious Mental Illness
}

Individuals with serious mental illness (SMI) die 25 years earlier, on average, than the general population and are designated a health disparity population (Parks, Svendsen, Singer, \& Foti, 2006). While the Internet provides exciting opportunities to support person-centered health care, web-based resources may convey barriers in terms of design and usability for this vulnerable population and, consequently, may contribute to even greater health disparities for individuals with SMI (Cohen \& Adams, 2011; Nicholson \& Rotondi, 2010; Swan, 2009). Many individuals with disabilities or chronic illness, including SMI, who use the Internet as a source of information report feeling frustrated, overwhelmed, or confused (Fox, 2007). As eHealth information resources embrace innovation and interactivity, and require increasingly more complex skills, individuals with SMI may become even more disenfranchised and disaffected (Chan \& Kaufman, 2011). Web design accommodations for this population have been recommended, but not generally applied (Rotondi, Eack, Hanusa, Spring, \& Haas, 2013). Barriers to the effective use of eHealth information by individuals with SMI must be overcome to promote health literacy, reduce health disparities and improve health outcomes (Nicholson \& Rotondi, 2010).

In October 2015, the University of Massachusetts Medical School (UMMS) was awarded grant funding from the National Library of Medicine to transform the existing UMMS eMentalHealth web site into a dynamic, interactive, wide-reaching eHealth resource for individuals with SMI. The eMental Health Bridges project will promote health literacy by developing, testing, and implementing: 1) eMH4me training modules to provide guidance for individuals with SMI on web-based information

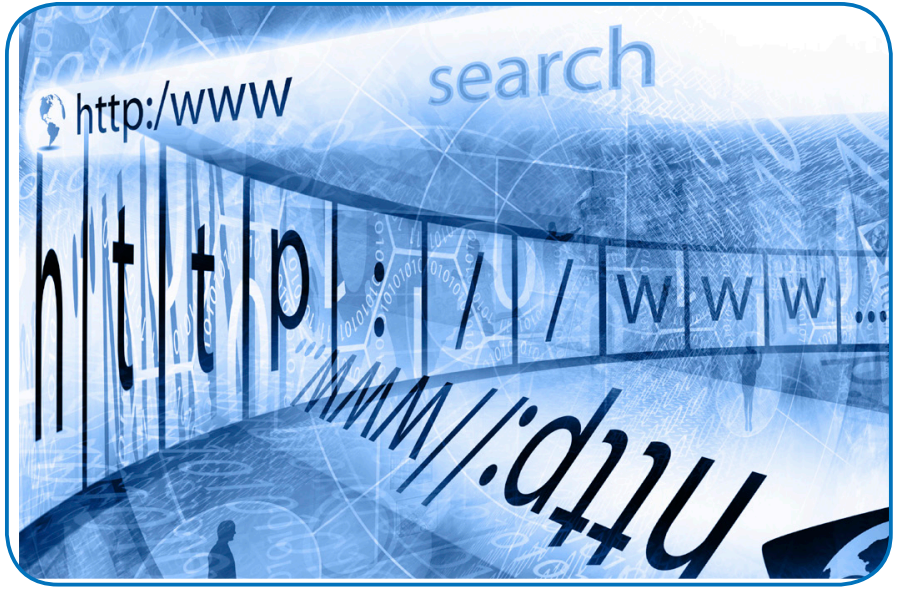

searching, judging source and site credibility, and interpreting data; and 2) web site prototypes that will serve as a connection to essential physical health information for individuals living with SMI. eMental Health Bridges will embrace user experience and design accommodations required for individuals with SMI to benefit fully from eHealth resources.

Over a three-year period, the eMental Health Bridges project team will work closely with individuals with SMI at each stage of the redesign process. Specific aims of eMH Bridges include:

1. Making strategic recommendations for eMH web site redesign including the $\mathrm{eMH} 4 \mathrm{me}$ training modules and the eMH Bridges prototype;

2. Conducting usability testing to develop fully functional web-based training modules and prototypes; and

3. Conducting remote testing of the acceptability and feasibility of the eMH4me training modules and $\mathrm{eMH}$ Bridges prototypes.

The multidisciplinary project team includes: Elaine Martin, DA (M/PI - UMMS/Lamar Soutter Library); Joanne Nicholson, PhD (M/PI - Dartmouth Psychiatric Rehabilitation Center/Geisel School of Medicine); Kathleen Biebel, PhD (Co-I - UMMS/Systems and Psychosocial Advances Research Center); Len Levin, MS-LIS, MA (Co-I - UMMS/Lamar Soutter Library); Zlatina Kostova, PhD (RC - UMMS/Department of Psychiatry). Design consultation will be provided by Scott Ahrens, MFA, Professor of Design at UMass Dartmouth and his design students. Mental health service consumers will be actively involved in providing input into the redesign as well as testing prototype components.

This is a product of Psychiatry Information in Brief. An electronic copy of this issue with full references can be found at http://escholarship.umassmed.edu/pib/vol13/iss1/1 


\section{References}

Chan, C. V., \& Kaufman, D. R. (2011). A framework for characterizing eHealth literacy demands and barriers. Journal of Medical Internet Research, 13(4), e94. http://doi.org/10.2196/jmir.1750

Cohen, R. A., \& Adams P. F. (2011, July). Use of the internet for health information: United States, 2009. (NCHS Data Brief 66). Retrieved from: http://www.ncbi.nlm.nih.gov/pubmed/22142942

Fox, S. E-patients with a chronic disability or chronic disease. (2007, October 8). Pew Internet \& American Life Project. Retrieved from: http://www.pewinternet.org/2007/10/08/e-patients-with-a-disability-or-chronic-disease/

NASMHPD Medical Directors Council Publications and Reports. (2006). Morbidity and mortality in people with serious mental illness. Parks, J., Svendsen, D., Singer, P., \& Foti, M. E (Eds.). Retrieved from: http://www.nasmhpd.org/content/ morbidity-and-mortality-people-serious-mental-illness

Nicholson, J., \& Rotondi, A. J. (2010). The internet, health promotion, and community participation. Psychiatric Services, 61(1), 96-97. doi: 10.1176/appi.ps.61.1.96-a

Rotondi, A. J., Eack, S. M., Hanusa, B. H., Spring, M. B., \& Haas, G. L. (2015). Critical design elements of e-health applications for users with severe mental illness: Singular focus, simple architecture, prominent contents, explicit navigation, and inclusive hyperlinks. Schizophrenia Bulletin, 41(2), 440-448. doi: 10.1093/schbul/sbt194

Swan, M. (2009). Emerging patient-driven health care models: An examination of health social networks, consumer personalized medicine and quantified self-tracking. International Journal of Environmental Research and Public Health, 6(2), 492-525. doi: 10.3390/ijerph6020492 